\title{
Effect of diabetes mellitus on short-term prognosis of 227 pyogenic liver abscess patients after hospitalization
}

\author{
Zhaoging Du, ${ }^{1,2}$, Xingchen Zhou ${ }^{1,2}$, Junzhou Zhao ${ }^{1,2}$, Jianbin Bi ${ }^{1,2}$, Yifan Ren ${ }^{1,2}$, Jia Zhang ${ }^{1,2}$, Yuxin Lin ${ }^{1,2}$,
} Zheng $\mathrm{Wu}^{2}$, Yi LV ${ }^{1,2}$, Xufeng Zhang ${ }^{1,2^{*}}$ and Rongqian $\mathrm{Wu}^{1 *}$

\begin{abstract}
Background: Pyogenic liver abscess (PLA) is an inflammatory disease with increasing incidence. When it occurs with diabetes mellitus (DM), the risk of recurrence and mortality may increase. However, the effect of DM on the short-term prognosis of PLA patients after hospitalization remained unknown.

Methods: Two hundred twenty-seven PLA patients who received treatment at the First Affiliated Hospital of Xi'an Jiaotong University from January 2011 to January 2018 were retrospectively enrolled. They were divided into two groups as the DM group $(n=61)$ and the Non-DM group $(n=166)$. In the DM group, HbA1C level $<7 \%$ was considered to be good-control of glycaemia $(n=23)$. The clinical characteristics and overall short-term survival were analyzed.

Results: The proportion of PLA patients with DM was 26.87\%. In the DM group, there was a higher incidence of hypertension and Candida spp. infection. Conservative administration and percutaneous drainage were mainly used in patients with good- (60.87\%) and poor-control (60.53\%) of glycaemia, respectively. During follow-up, 24 (10.57\%) died due to uncontrolled systemic infections and other serious complications. Compared with PLA patients without DM, patients in the DM group had significantly increased 6-month mortality rate after discharge (Log-Rank test, $P=$ 0.021). Poor-control of glycaemia did not reduce the six-month survival, while the recurrence rate of PLA within 3 months showed an almost 3-fold increase (13.16\% vs. 4.35\%). Further multivariate analyses found that DM was the only independent risk factor for the PLA six-month survival (odds ratio [OR]: 3.019, 95\% confidence interval [CI]: 1.138-8.010, $P=0.026)$. However, the blood glucose level had no significant effect on the short-term survival of PLA patients with DM (Log-Rank test, $P=0.218$ ).
\end{abstract}

Conclusions: In PLA patients, DM aggravated short-term mortality and blood glucose levels should be well controlled.

Keywords: Diabetes mellitus, Pyogenic liver abscess, Prognosis, Survival

\section{Background}

Pyogenic liver abscess (PLA), as a serious infectious disease occurs in the liver parenchyma, has shown a trend of increasing incidence and high mortality recently [1]. Researchers found that PLA had different prevalence in

\footnotetext{
*Correspondence: xfzhang125@126.com; xfzhang125@mail.xjtu.edu.cn; rwu001@mail.xjtu.edu.cn

${ }^{1}$ National-Local Joint Engineering Research Center for Precision Surgery \& Regenerative Medicine, Shaanxi Provincial Center for Regenerative Medicine and Surgical Engineering, First Affiliated Hospital of Xi'an Jiaotong University, Xi'an 710061, Shaanxi Province, China

Full list of author information is available at the end of the article
}

general population over the world, with a ranging from 4 per 10,000 [2] in Europe and Americas to between 18 and 86 per 10,000 [1,3] in Asia. Because it can cause fatal systemic infections, the mortality rate of PLA within 30 days of hospitalization can be as high as $10 \%$ [4]. Especially in the case of combining high risk factors or underlying conditions, serious complications and worse prognosis are more likely [5].

The DM prevalence is relatively high among PLA patients and can be up to $35.3 \%$ [4]. Meanwhile, DM status may easier result in severe complications and recurrent

(c) The Author(s). 2020 Open Access This article is distributed under the terms of the Creative Commons Attribution 4.0 International License (http://creativecommons.org/licenses/by/4.0/), which permits unrestricted use, distribution, and reproduction in any medium, provided you give appropriate credit to the original author(s) and the source, provide a link to the Creative Commons license, and indicate if changes were made. The Creative Commons Public Domain Dedication waiver (http://creativecommons.org/publicdomain/zero/1.0/) applies to the data made available in this article, unless otherwise stated. 
infection [6]. In addition, poor-control of blood glucose may aggravate the situation and prognosis [7]. However, the clinical characteristics and short-term survival between PLA patients with and without DM have not been fully investigated before, especially in northwest China. Moreover, research has rarely been published about the effect of blood glycaemic control on these aspects of PLA patients with DM. In this study, we conducted a retrospective study on PLA patients with or without $\mathrm{DM}$, and with good or poor control of blood glucose level, comparing their clinical characteristics and shortterm survivals, which might help to improve the diagnosis and prognosis of PLA patients with DM and provide clues of the effect of glycaemic control.

\section{Methods}

\section{Patients}

In this retrospective study, we examined the patients who were diagnosed primarily as PLA in the First Affiliated Hospital of Xi'an Jiaotong University between January 2011 to January 2018. All diagnoses of PLA were based on the clinical features, imaging and laboratory results, blood and pus cultures. Details of 422 patients were retrieved through the hospital's electronic medical record system. Patients with the following conditions were excluded: those who were diagnosed with malignant tumors or other serious cardiovascular diseases, those who were not the first-time suffering from liver abscess, those who had not finished the hospitalization in our center and those who had incomplete medical records or a 180 days follow-up. Finally, 227 patients entered this study (Additional file 1: Table S1). Patients were firstly divided into two groups based on the diagnoses with or without diabetes, and then the patients with diabetes were further divided into two subgroups, good- and poor-control groups of glycaemia. Patients of type II diabetes mellitus all had a clear history of diabetes at admission, and none of them were diagnosed after admission. We defined DM patients with HbA1C level $<7 \%$ included in the good-control group and $\geq 7 \%$ in the poor-control group. This study was strictly complied with the Treaty of Helsinki and approved by the ethics committee of the First Affiliated Hospital of Xi'an Jiaotong University. Written informed consent were waived as a retrospective research.

\section{Data collection}

All data were collected from the electronic medical records system. The general data we extracted included age, sex, symptoms and signs, underlying conditions, hepatitis status, medicine use, cost and length of hospital stay. Laboratory results at admission were obtained, containing blood routine, liver function, renal function, coagulation, blood and pus culture data (involved those who had either and those who had both), plasma glucose, HbA1C level and diabetic vascular diseases.

Diabetic macro-angiopathy collected cardio- and cerebrovascular accidents and lower extremity gangrene, and micro-angiopathy included microvascular lesions of retina and kidney caused by high blood glucose levels. Complications, treatments and outcomes were also gained. Abscess number, diameter, site and gas-forming were measured by ultrasonography and computerized tomography $(\mathrm{CT})$.

\section{Follow-up}

Follow-up for all patients was until June 2018 and lasted for at least 6 months after discharge. The average followup time was 820 (IQR: 308, 1261) days. The main contents of the follow-up included the disease status and recurrence of all patients. All patients achieved full followup data. The mortality outcome was ascertained from discharge time to the last follow-up. To minimize classification errors, the follow-up was completed by two clinical researchers independently.

\section{Statistical analysis}

For continuous variables, the study was expressed as mean \pm standard deviation or median (min-max) whereas categorical variables used frequency and percentage. To calculate the difference between the two groups, we applied the Student's t-test or Wilcoxon test for continuous variables and the chi-squared test or Fisher's exact test for categorical data. For three or more groups, we applied the analysis of variance. The factors that found $P<0.10$ in the univariate analysis were carried forward through the multivariate analysis. Survival curves were calculated by the Kaplan-Meier curve method, and statistical differences were calculated through the Log-Rank test. All statistical analyses were finished by SPSS 23.0 software (IBM Corporation, Armonk, NY, USA). Graphpad prism 8.0 software was used to beautify the survival curves (GraphPad Software, Inc. La Jolla, USA). $P<0.05$ was considered as statistically significant.

\section{Results}

\section{Demographic and clinical characteristics}

A total of 227 patients with PLA were enrolled in this retrospective study. As shown in Table 1, the average age of total patients was 56 years (range: 11-84 years), and 135 (59.47\%) of them were male. Among them, 66 (29.07\%) patients had a history of smoking, 43 (18.94\%) patients had alcohol drinking history. 43 (18.94\%) and 8 (3.52\%) patients had hypertension and cirrhosis, respectively. Most patients had a normal $(60.79 \%)$ or low-grade fever temperature (34.80\%) at admission, and the medium time for temperature normalization was 6.39 
Table 1 Clinical characteristics of the 227 patients with pyogenic liver abscess patients with diabetes or without diabetes presented at admission

\begin{tabular}{|c|c|c|c|c|}
\hline Values & Median (range)/n (percentage) & Diabetes mellitus & Non-diabetes mellitus & $p$ value \\
\hline$n$ & 227 & $61(26.87 \%)$ & $166(73.13 \%)$ & \\
\hline Age (years) & $56(11-84)$ & $57(22-84)$ & $56(11-84)$ & 0.837 \\
\hline Gender (male) & $135(59.47 \%)$ & $39(63.93 \%)$ & 96 (57.83\%) & 0.406 \\
\hline \multicolumn{5}{|l|}{ Underlying conditions } \\
\hline Smoking & 66 (29.07\%) & $16(26.23 \%)$ & 50 (30.12\%) & 0.567 \\
\hline Drinking & $43(18.94 \%)$ & $33(19.88 \%)$ & $10(16.39 \%)$ & 0.552 \\
\hline Hypertension & $43(18.94 \%)$ & $31(50.82 \%)$ & $12(7.23 \%)$ & $<0.001$ \\
\hline Cirrhosis & $8(3.52 \%)$ & $2(3.28 \%)$ & $6(3.61 \%)$ & 0.902 \\
\hline \multicolumn{5}{|l|}{ Body temperature at admission $\left({ }^{\circ} \mathrm{C}\right)$} \\
\hline $35.5^{\circ} \mathrm{C} \sim 37.3^{\circ} \mathrm{C}$ & $138(60.79 \%)$ & $42(68.85 \%)$ & $96(57.83 \%)$ & \multirow[t]{3}{*}{0.319} \\
\hline $37.4^{\circ} \mathrm{C} \sim 39^{\circ} \mathrm{C}$ & $79(34.80 \%)$ & $17(27.87 \%)$ & $62(37.35 \%)$ & \\
\hline$>39.1^{\circ} \mathrm{C}$ & $10(4.41 \%)$ & $2(3.28 \%)$ & $8(4.82 \%)$ & \\
\hline Time for temperature normalization (days) & $6.39(0-40)$ & $6.05(0-24)$ & $6.51(0-40)$ & 0.593 \\
\hline \multicolumn{5}{|l|}{ Laboratory tests } \\
\hline$W B C>10 \times 10^{9} / L$ & $119(52.42 \%)$ & $23(37.70 \%)$ & $96(57.83 \%)$ & 0.007 \\
\hline $\mathrm{WBC}<3.5 \times 10^{9} / \mathrm{L}$ & $4(1.76 \%)$ & $3(4.92 \%)$ & $1(0.60 \%)$ & 0.105 \\
\hline $\mathrm{ALT}>40 \mathrm{U} / \mathrm{L}$ & $108(47.58 \%)$ & $25(40.98 \%)$ & $83(50.00 \%)$ & 0.228 \\
\hline $\mathrm{AST}>40 \mathrm{U} / \mathrm{L}$ & $67(29.52 \%)$ & $15(24.59 \%)$ & $52(31.33 \%)$ & 0.324 \\
\hline$A L B<35 \mathrm{~g} / \mathrm{L}$ & $169(74.45 \%)$ & $45(73.77 \%)$ & $124(74.70 \%)$ & 0.887 \\
\hline TBIL $>17 \mu \mathrm{mol} / \mathrm{L}$ & $96(42.29 \%)$ & $31(50.82 \%)$ & 65 (39.16\%) & 0.115 \\
\hline $\mathrm{PT}>17 \mathrm{~s}$ & $20(8.81 \%)$ & $6(9.84 \%)$ & $14(8.43 \%)$ & 0.741 \\
\hline $\mathrm{APTT}>45 \mathrm{~s}$ & $26(11.45 \%)$ & $7(11.48 \%)$ & $19(11.45 \%)$ & 0.995 \\
\hline $\mathrm{BUN}>7.2 \mathrm{mmol} / \mathrm{L}$ & $16(7.27 \%)$ & $7(11.67 \%)$ & $9(5.63 \%)$ & 0.213 \\
\hline $\mathrm{Cr}>97 \mu \mathrm{mol} / \mathrm{L}$ & $30(13.64 \%)$ & $7(11.67 \%)$ & $23(14.37 \%)$ & 0.602 \\
\hline \multicolumn{5}{|l|}{ Abscess number } \\
\hline Solitary abscess & $172(75.77 \%)$ & $47(77.05 \%)$ & $125(75.30 \%)$ & \multirow[t]{2}{*}{0.785} \\
\hline Multiple abscess & $55(24.23 \%)$ & $14(22.95 \%)$ & $41(24.70 \%)$ & \\
\hline \multicolumn{5}{|l|}{ Maximal diameter of abscess } \\
\hline$\leq 5 \mathrm{~cm}$ & 75 (33.04\%) & $24(39.34 \%)$ & $51(30.72 \%)$ & \multirow[t]{3}{*}{0.116} \\
\hline $5 \sim 10 \mathrm{~cm}$ & $132(58.15 \%)$ & $34(55.74 \%)$ & 98 (59.04\%) & \\
\hline$>10 \mathrm{~cm}$ & $20(8.81 \%)$ & $3(4.92 \%)$ & $17(10.24 \%)$ & \\
\hline \multicolumn{5}{|l|}{ Abscess site } \\
\hline Left lobe & $34(14.98 \%)$ & $6(9.84 \%)$ & $28(16.87 \%)$ & \multirow[t]{4}{*}{0.289} \\
\hline Right lobe & $137(60.35 \%)$ & $43(70.49 \%)$ & $94(56.63 \%)$ & \\
\hline Both left and right & $41(18.06 \%)$ & $9(14.75 \%)$ & $32(19.28 \%)$ & \\
\hline Other sites & $15(6.61 \%)$ & $3(4.92 \%)$ & $12(7.23 \%)$ & \\
\hline Gas forming & $45(19.82 \%)$ & $15(24.59 \%)$ & $30(18.07 \%)$ & 0.275 \\
\hline \multicolumn{5}{|l|}{ Medicine use } \\
\hline Steroid hormone & $57(25.11 \%)$ & $21(34.43 \%)$ & $36(21.69 \%)$ & 0.050 \\
\hline Hepatoprotective drugs & $126(55.51 \%)$ & $36(59.02 \%)$ & 90 (54.22\%) & 0.519 \\
\hline Immune response enhancer & $42(18.50 \%)$ & $24(39.34 \%)$ & $18(10.84 \%)$ & $<0.001$ \\
\hline
\end{tabular}

WBC white blood cell, $A L T$ alanine transaminase, $A S T$ aspartate transaminase, $A L B$ albumin, TBIL total bilirubin, $P T$ prothrombin time, APTT activated partial thromboplastin time, BUN blood urea nitrogen, $C r$ creatinine 
(range: 0-40). leucocytes abnormally increased in 119 patients $(52.42 \%)$ on the first day of admission. In this cohort, the number of the abscess was mainly single (75.77\%). The maximum diameter of the abscess in 132 patients $(58.15 \%)$ was between 5 and $10 \mathrm{~cm}$, then followed by a small abscess in 75 cases (33.04\%). In 137 $(60.35 \%)$ patients, the abscess located in the right liver lobe, $34(14.98 \%)$ in the left, and $41(18.06 \%)$ in both. Gas formation was observed in 45 patients (19.82\%). In Table 2, 116 blood cultures were collected and only 28 patients $(24.14 \%)$ were positive. There was no significant difference in the positive proportion between the two groups. Based on pus culture from 148 cases, positive growth was found in 98 patients (66.22\%). Among the positive patients, 114 patients $(85.07 \%)$ were Gramnegative bacteria, 18 (13.43\%) were Gram-positive bacteria, and 2 (1.49\%) were Candida spp. infections. Klebsiella pneumonia and Escherichia coli in the Gramnegative organisms were the two most common bacteria in this study, accounting for 57.46 and $17.91 \%$, respectively. In the Gram-positive organisms, Streptococcus spp. (6.72\%) was the most pathogens cultured. It was documented that pleural and celiac effusion were the most common complications (18.41, and $7.58 \%$, respectively, Table 3). 136 (59.91\%) patients received percutaneous drainage, 28 (12.33\%) underwent surgical drainage, and the rest $63(27.75 \%)$ were administrated conservative treatment. $125(55.07 \%)$ patients presented combined antibiotic use. All patients showed outcomes with cured or improved and no patient died during the hospital stay. The average cost of total patients was 4096 dollars.

\section{Associations between diabetes mellitus and patient characteristics}

In this study, 227 patients were divided into two groups based on DM. The Non-DM group included 166 (73.13\%) patients and the DM group included 61 (26.87\%) patients, with an average diabetes duration time of 5.5 years (range: $0.2-30$ years). There was no significant difference in gender, age, body temperature at admission, abscess number, size, site, and gas-forming between the two groups (Table 1). However, patients in the DM group exhibited more hypertension but lower leucocytes count $(P<0.001$, and $P=0.007$, respectively). Interestingly, the use of steroid hormone $(34.43 \%$ vs. $21.69 \%)$ and immune response enhancer $(39.34 \%$ vs. $10.84 \%)$ was significantly higher in PLA patients with DM than in the non-DM group $(P<0.05)$. Although the infection of Gram-negative and -positive in this study were similar between the two groups, patients in the DM group had higher Candida spp. infection than that of in Non-DM group $(P=0.052$, Table 2$)$. In Table 3 , no

Table 2 Blood and pus cultures in pyogenic liver abscess patients with diabetes mellitus (DM) and non-diabetes mellitus (Non-DM)

\begin{tabular}{|c|c|c|c|c|}
\hline \multirow[t]{2}{*}{ Values } & \multicolumn{2}{|l|}{ Blood culture } & \multicolumn{2}{|l|}{ Pus culture } \\
\hline & $\mathrm{DM}(n=34)$ & $\begin{array}{l}\text { Non-DM } \\
(n=82)\end{array}$ & $\mathrm{DM}(n=34)$ & $\begin{array}{l}\text { Non-DM } \\
(n=114) \\
\end{array}$ \\
\hline Positive results & 10 & 18 & 25 & 73 \\
\hline Polymicrobial results & 1 & 2 & 1 & 4 \\
\hline \multicolumn{5}{|l|}{ Gram-negative organisms } \\
\hline Klebsiella pneumonia & 3 & 12 & 15 & 47 \\
\hline Escherichia coli & 4 & 3 & 5 & 12 \\
\hline Pseudomonas aeruginosa & 1 & 0 & 2 & 1 \\
\hline Enterobacter cloacae & 0 & 0 & 0 & 2 \\
\hline Proteus spp. & 0 & 0 & 0 & 2 \\
\hline Serratia fonticola & 0 & 1 & 0 & 0 \\
\hline Salmonella enteritidis & 0 & 0 & 1 & 0 \\
\hline Klebsiella oxytoca & 0 & 0 & 0 & 1 \\
\hline Bacillus citrate & 0 & 0 & 0 & 1 \\
\hline Stenotrophomonas maltophilia & 0 & 0 & 1 & 0 \\
\hline \multicolumn{5}{|l|}{ Gram-positive organisms } \\
\hline Streptococcus spp. & 1 & 1 & 0 & 7 \\
\hline Enterococcus spp. & 2 & 0 & 0 & 3 \\
\hline Clostridium spp. & 0 & 2 & 0 & 0 \\
\hline Staphylococcus spp. & 0 & 1 & 0 & 1 \\
\hline Candida spp. & 0 & 0 & 2 & 0 \\
\hline
\end{tabular}


Table 3 Complications, treatments, outcomes and survival of the pyogenic liver abscess patients with diabetes mellitus and nondiabetes mellitus

\begin{tabular}{|c|c|c|c|c|}
\hline Variables & Median (range)/n (percentage) & Diabetes mellitus & Non-diabetes mellitus & $p$ value \\
\hline \multicolumn{5}{|l|}{ Complications } \\
\hline Bile leakage & $9(3.96 \%)$ & $2(3.28 \%)$ & $7(4.22 \%)$ & 1.000 \\
\hline Intraperitoneal bleeding & $10(4.41 \%)$ & $3(4.92 \%)$ & $7(4.22 \%)$ & 0.731 \\
\hline Plumonary infection & $5(2.20 \%)$ & $2(3.28 \%)$ & $3(1.81 \%)$ & 0.613 \\
\hline Pleural effusion & $51(18.41)$ & $17(27.87 \%)$ & $34(20.48 \%)$ & 0.237 \\
\hline Celiac effusion & $21(7.58)$ & $8(13.11 \%)$ & $13(7.83 \%)$ & 0.208 \\
\hline \multicolumn{5}{|l|}{ Treatments } \\
\hline Percutaneous drainage & $136(59.91 \%)$ & $29(47.54 \%)$ & $107(64.46 \%)$ & \multirow[t]{3}{*}{0.024} \\
\hline Surgical drainage & $28(12.33 \%)$ & $7(11.48 \%)$ & $21(12.65 \%)$ & \\
\hline Conservative treatment & $63(27.75 \%)$ & $25(40.98 \%)$ & $38(22.89 \%)$ & \\
\hline \multicolumn{5}{|l|}{ Antibiotic use } \\
\hline Combined & $125(55.07 \%)$ & $37(60.66 \%)$ & $88(53.01 \%)$ & \multirow[t]{2}{*}{0.305} \\
\hline Single & $102(44.93 \%)$ & $24(39.34 \%)$ & 78 (46.99\%) & \\
\hline \multicolumn{5}{|l|}{ Outcomes } \\
\hline Cured & $155(68.28 \%)$ & $45(73.77 \%)$ & $110(66.27 \%)$ & \multirow[t]{3}{*}{0.282} \\
\hline Improved & $72(31.72 \%)$ & $16(26.23 \%)$ & $56(33.73 \%)$ & \\
\hline Death & $0(0 \%)$ & $0(0 \%)$ & $0(0 \%)$ & \\
\hline Hospital stay (days) & $14(2-52)$ & $15(3-40)$ & $14(2-52)$ & 0.444 \\
\hline Total hospitalization expenses ( $\times 1000$ dollars) & $4.10(0.39-27.16)$ & $4.24(0.39-27.16)$ & $4.05(0.47-18.05)$ & 0.748 \\
\hline Reoccurrence in three months & $14(6.17 \%)$ & $6(9.84 \%)$ & $8(21.05 \%)$ & 0.164 \\
\hline Survival/Death in six months & $\begin{array}{l}203(89.43 \%) \\
/ 24(10.57 \%)\end{array}$ & $\begin{array}{l}50(81.97 \%) \\
/ 11(18.03 \%)\end{array}$ & $\begin{array}{l}153(92.17 \%) \\
/ 13(7.83 \%)\end{array}$ & 0.027 \\
\hline
\end{tabular}

significant difference had been found in complications, intravenous antibiotics use, outcomes, hospital stay, total costs and reoccurrence in 3 months between the two groups. While the choice of treatments was different between the two groups $(P=0.024)$. Percutaneous drainage was mainly adopted in patients without DM (64.46\%), while percutaneous drainage and conservative treatment were mainly performed in patients with DM (47.54 and $40.98 \%)$.

\section{Effect of diabetes mellitus on short-term survival in liver abscess patients}

During the follow-up period, 24 (10.57\%) died within 6 months and 14 (6.17\%) were diagnosed with PLA recurrence within 3 months after discharge. The PLA patients with DM had lower six-month survival than that of in Non-DM group $(81.97 \%$ vs. $92.17 \%, P=0.027)$ and no significant difference had been found with the reoccurrence rate between the two groups $(P=0.164$, Table 3$)$. To explore risk factors independently associated with short-term survival after hospitalization in PLA patients, univariable and multivariable analysis were made. Univariate variables with $P<0.10$ were further analyzed with a multivariate model. As shown in Table 4, diabetes mellitus (OR: 3.019 , 95\% CI:1.138-8.010, $P=0.026$ ) was the only independent risk factor for six-month survival after discharge. Other factors including age $>60$ years, gender, cirrhosis, biliary tract infection, abscess number and size, gas forming, Escherichia coli infection, and treatment methods were not found to be independent risk factors. The Kaplan-Meier curve of six-month survival after discharge was further estimated concerning DM in Fig. 1. It was found that PLA patients with DM had worse short-term survival than those in the NonDM group (Log-Rank test, $P=0.021$ ).

\section{Subgroups analysis in PLA patients with DM}

Abnormal glycaemia level in the DM group was considered as a potent risk factor of short-term survival in PLA patients, which was further investigated in subgroups. All the patients were classified into two subgroups according to the HbA1C level. The clinical characteristics, laboratory results, abscess information, treatments and outcomes were compared between the two subgroups in Table 5. No difference was presented between the two subgroups in age, gender, diabetes duration time, underlying conditions, diabetic vascular diseases, laboratory tests, abscess characteristics, medicine 
Table 4 Univariate and multivariate analysis of factors associated with PLA six-month survival

\begin{tabular}{|c|c|c|c|c|}
\hline \multirow[t]{2}{*}{ Variables } & \multicolumn{2}{|l|}{ Univariate analysis } & \multicolumn{2}{|l|}{ Multivariate analysis } \\
\hline & OR (95\%Cl) & P & OR $(95 \% \mathrm{Cl})$ & $P$ \\
\hline Age $>60$ years & $2.261(0.517-9.507)$ & 0.284 & & \\
\hline Gender (male) & $0.395(0.092-1.627)$ & 0.212 & & \\
\hline Smoking (yes/no) & $1.486(0.345-6.404)$ & 0.595 & & \\
\hline Drinking (yes/no) & $1.447(0.282-7.430)$ & 0.658 & & \\
\hline Hypertension (yes/no) & $1.447(0.282-7.430)$ & 0.658 & & \\
\hline Cirrhosis (yes/no) & $4.327(0.467-40.094)$ & 0.197 & & \\
\hline Diabetes (yes/no) & $2.589(1.091-6.144)$ & 0.031 & 3.019 (1.138-8.010) & 0.026 \\
\hline Biliary tract infection (yes/no) & $0.835(0.099-7.015)$ & 0.868 & & \\
\hline Leucocytes $>10 \times 10^{9} / \mathrm{L}$ & $0.533(0.124-2.284)$ & 0.397 & & \\
\hline Hemoglobin < $120 \mathrm{~g} / \mathrm{L}$ & $0.536(0.106-2.716)$ & 0.451 & & \\
\hline Platelet count $<100 \times 10^{9} / \mathrm{L}$ & $1.161(0.137-9.843)$ & 0.891 & & \\
\hline TBIL $>17 \mu \mathrm{mol} / \mathrm{L}$ & $2.344(0.546-10.058)$ & 0.252 & & \\
\hline $\mathrm{PT}>17 \mathrm{~s}$ & $3.722(0.700-19.800)$ & 0.150 & & \\
\hline $\mathrm{BUN}>7.2 \mathrm{mmol} / \mathrm{L}$ & $2.19(0.421-11.394)$ & 0.351 & & \\
\hline $\mathrm{Cr}>97 \mu \mathrm{mol} / \mathrm{L}$ & $1.876(0.216-16.27)$ & 0.568 & & \\
\hline Abscess number & $0.382(0.046-3.175)$ & 0.373 & & \\
\hline Diameter of abscess & $1.029(0.337-3.141)$ & 0.960 & & \\
\hline Abscess site & $1.822(0.905-3.667)$ & 0.093 & $2.156(0.832-5.586)$ & 0.114 \\
\hline Gas-forming & $5.024(0.531-47.518)$ & 0.159 & & \\
\hline Klebsiella pneumonia infection & $0.315(0.036-2.758)$ & 0.297 & & \\
\hline Escherichia coli infection & $2.194(0.904-5.325)$ & 0.083 & $0.226(0.038-1.339)$ & 0.101 \\
\hline Treatments & $1.046(0.327-3.344)$ & 0.940 & & \\
\hline
\end{tabular}

TBIL total bilirubin, PT prothrombin time, BUN blood urea nitrogen, Cr creatinine

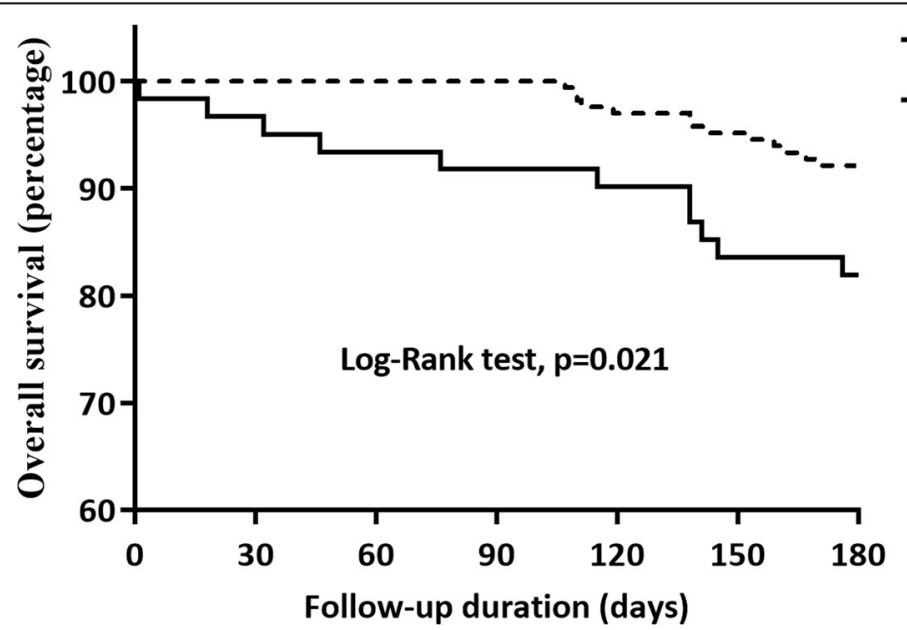

Fig. 1 Effect of diabetes mellitus on six-month survival in PLA patients after discharge. Differences in short-term survival rates between PLA patients who combined with diabetes (DM group) and those who did not combine with diabetes (Non-DM group). The survival rate was assessed by the Kaplan-Meier analysis and compared by the Log-Rank test 
Table 5 The clinical characteristics of pyogenic liver abscess with DM between poor-control of glycaemia group and good-control of glycaemia group

\begin{tabular}{|c|c|c|c|}
\hline Variables & good-control of glycaemia $(n=23)$ & poor-control of glycaemia $(n=38)$ & $p$ value \\
\hline Age (years) & $57(22-84)$ & $58(23-80)$ & 0.951 \\
\hline Gender (male) & $15(65.22 \%)$ & $24(63.16 \%)$ & 0.871 \\
\hline Diabetes duration (years) & $5.4(0.4-27)$ & $5.5(0.2-30)$ & 0.952 \\
\hline \multicolumn{4}{|l|}{ Underlying condition } \\
\hline Smoking & $8(34.78 \%)$ & $8(21.05 \%)$ & 0.237 \\
\hline Drinking & $5(21.74 \%)$ & $5(13.16 \%)$ & 0.603 \\
\hline Hypertension & $6(27.27 \%)$ & $6(15.79 \%)$ & 0.461 \\
\hline \multicolumn{4}{|l|}{ Diabetic vascular diseases } \\
\hline Micro-angiopathy & $2(8.70 \%)$ & $8(21.05 \%)$ & 0.294 \\
\hline Macro-angiopathy & $2(8.70 \%)$ & $3(7.89 \%)$ & 1.000 \\
\hline \multicolumn{4}{|l|}{ Laboratory tests } \\
\hline $\mathrm{WBC}>10 \times 10^{9} / \mathrm{L}$ & $7(30.43 \%)$ & $16(42.11 \%)$ & 0.362 \\
\hline $\mathrm{WBC}<3.5 \times 10^{9} / \mathrm{L}$ & $2(8.70 \%)$ & $1(2.63 \%)$ & 0.652 \\
\hline $\mathrm{ALT}>40 \mathrm{U} / \mathrm{L}$ & $12(52.17 \%)$ & $13(34.21 \%)$ & 0.167 \\
\hline AST $>40 \mathrm{U} / \mathrm{L}$ & $7(30.43 \%)$ & $8(21.05 \%)$ & 0.410 \\
\hline$A L B<35 \mathrm{~g} / \mathrm{L}$ & $16(69.57 \%)$ & $29(76.32 \%)$ & 0.561 \\
\hline $\mathrm{TBIL}>17 \mu \mathrm{mol} / \mathrm{L}$ & $14(60.87 \%)$ & $17(44.74 \%)$ & 0.222 \\
\hline $\mathrm{PT}>17 \mathrm{~s}$ & $4(17.39 \%)$ & $2(5.26 \%)$ & 0.272 \\
\hline $\mathrm{APTT}>45 \mathrm{~s}$ & $3(13.04 \%)$ & $4(10.53 \%)$ & 1.000 \\
\hline $\mathrm{BUN}>7.2 \mathrm{mmol} / \mathrm{L}$ & $2(8.70 \%)$ & $5(13.51 \%)$ & 0.697 \\
\hline $\mathrm{Cr}>97 \mu \mathrm{mol} / \mathrm{L}$ & $2(8.70 \%)$ & $5(13.51 \%)$ & 0.697 \\
\hline \multicolumn{4}{|l|}{ Abscess number } \\
\hline Solitary abscess & $18(78.26 \%)$ & $29(76.32 \%)$ & 0.861 \\
\hline Multiple abscess & $5(21.74 \%)$ & $9(23.68 \%)$ & \\
\hline \multicolumn{4}{|l|}{ Maximal diameter of abscess } \\
\hline$\leq 5 \mathrm{~cm}$ & $11(47.83 \%)$ & $13(34.21 \%)$ & 0.178 \\
\hline $5 \sim 10 \mathrm{~cm}$ & $11(47.83 \%)$ & $23(60.53 \%)$ & \\
\hline$>10 \mathrm{~cm}$ & $1(4.35 \%)$ & $2(5.26 \%)$ & \\
\hline \multicolumn{4}{|l|}{ Abscess site } \\
\hline Left lobe & $4(17.39 \%)$ & $2(5.36 \%)$ & 0.220 \\
\hline Right lobe & $13(56.52 \%)$ & $30(78.95 \%)$ & \\
\hline Both left and right & $5(21.74 \%)$ & $4(10.53 \%)$ & \\
\hline Other sites & $1(4.35 \%)$ & $2(5.26 \%)$ & \\
\hline \multicolumn{4}{|l|}{ Medicine use } \\
\hline Steroid hormone & $10(43.48 \%)$ & $11(28.95 \%)$ & 0.247 \\
\hline Hepatoprotective drugs & $14(60.87 \%)$ & $22(57.89 \%)$ & 0.819 \\
\hline Immune response enhancer & $10(43.48 \%)$ & $14(36.84 \%)$ & 0.607 \\
\hline Klebsiella pneumonia infection & $4(17.39 \%)$ & $11(28.95 \%)$ & 0.310 \\
\hline Escherichia coli infection & $2(8.70 \%)$ & $3(7.89 \%)$ & 1.000 \\
\hline \multicolumn{4}{|l|}{ Treatments } \\
\hline Percutaneous drainage & $6(26.09 \%)$ & $23(60.53 \%)$ & 0.027 \\
\hline Surgical drainage & $3(13.04 \%)$ & $4(10.53 \%)$ & \\
\hline Conservative treatment & $14(60.87 \%)$ & $11(28.95 \%)$ & \\
\hline
\end{tabular}


Table 5 The clinical characteristics of pyogenic liver abscess with DM between poor-control of glycaemia group and good-control of glycaemia group (Continued)

\begin{tabular}{|c|c|c|c|}
\hline Variables & good-control of glycaemia $(n=23)$ & poor-control of glycaemia $(n=38)$ & $p$ value \\
\hline \multicolumn{4}{|l|}{ Antibiotic use } \\
\hline Combined & $10(43.48 \%)$ & $27(71.05 \%)$ & \multirow[t]{2}{*}{0.033} \\
\hline Single & $13(56.52 \%)$ & $11(28.95 \%)$ & \\
\hline \multicolumn{4}{|l|}{ Outcomes } \\
\hline Cured & $16(69.57 \%)$ & $29(76.34 \%)$ & \multirow[t]{3}{*}{0.565} \\
\hline Improved & $7(30.43 \%)$ & $9(23.68 \%)$ & \\
\hline Death & $0(0 \%)$ & $0(0 \%)$ & \\
\hline Hospital stay (days) & $15(3-40)$ & $15(3-28)$ & 0.986 \\
\hline Total Hospitalization expenses $(\times 1000$ dollars) & $2.21(3.15-7.79)$ & $6.04(0.61-27.16)$ & 0.056 \\
\hline Reoccurrence in three months & $1(4.35 \%)$ & $5(13.16 \%)$ & 0.395 \\
\hline Survival (yes/no) in six months & $17(73.91 \%)$ & $33(86.84 \%)$ & 0.353 \\
\hline
\end{tabular}

WBC white blood cell, $A L T$ alanine transaminase, $A S T$ aspartate transaminase, $A L B$ albumin, $T B I L$ total bilirubin, $P T$ prothrombin time, $A P T T$ activated partial thromboplastin time, BUN blood urea nitrogen, $\mathrm{Cr}$ creatinine

use, outcomes, and hospital stay, etc. However, there was an obvious difference in the selection of treatments between the two subgroups $(P=0.027)$. Percutaneous drainage was mainly performed in patients with poorcontrol of glycaemia (60.53\%) and conservative treatment was mainly adopted in patients with good-control of glycaemia (60.87\%). Besides, combined intravenous antibiotics showed a higher proportion in poor-control group $(71.05 \%, P=0.033)$. Although there was no significant difference, total hospitalization costs and relapsed PLA within 3 months after discharge showed an obvious increase in the poor-control group compared to goodcontrol group (6037 vs. 3154 dollars, $13.16 \%$ vs. $4.35 \%$, respectively). Kaplan-Meier curve with different glycaemia levels in terms of six-month survival was shown in Fig. 2. No difference was unfolded between the two groups in Kaplan-Meier plots (Log-Rank test, $P=0.218$ ).

\section{Discussion}

The increasing incidence and high mortality of PLA patients with diabetes mellitus has become an important health problem in the hepatobiliary system that plagues humans [6]. As a risk factor for PLA, DM can directly lead to liver damage, abnormal bile secretion, and increasing portal vein infection [8-10]. DM can also cause systemic metabolic disorders and impaired immunity, which weakens the ability of the liver to clear bacteria, making the bacteria easy to colonize and multiply to form abscesses [11]. Studies have confirmed that although the incidence of DM in PLA patients is

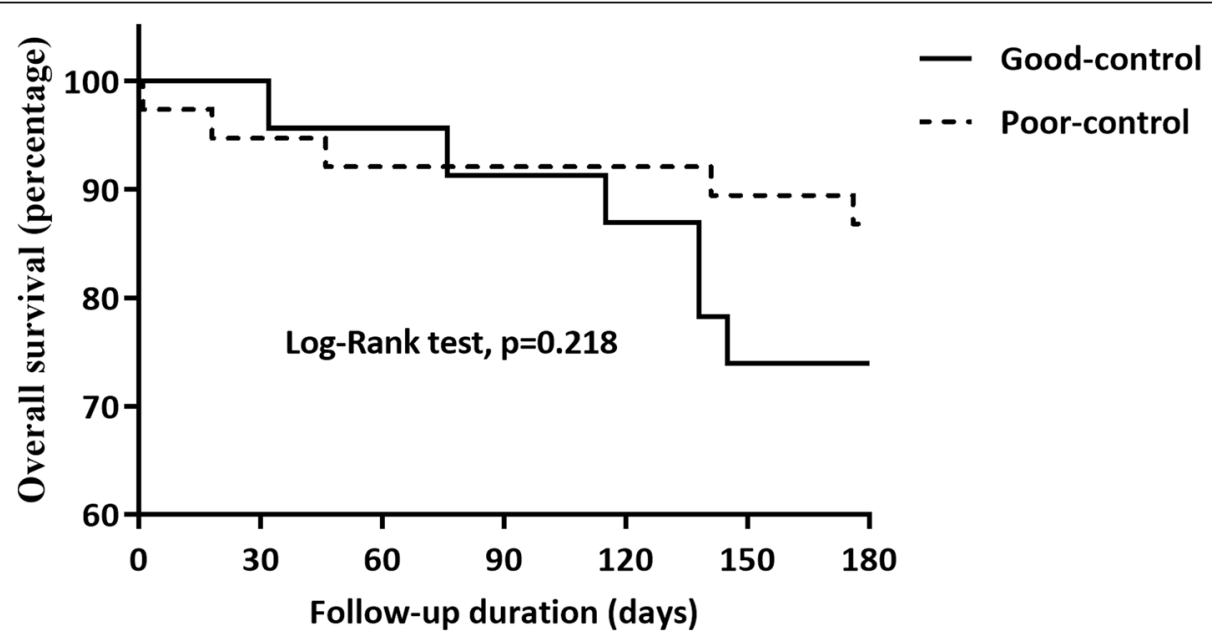

Fig. 2 Effect of controlled blood glycaemia level on six-month survival in PLA patients with diabetes after discharge. Differences in short-term survival rates between PLA patients with diabetes who performed with good-control of glycaemia (Good-control group) and those who did not (Poor-control group). The survival rate was assessed by the Kaplan-Meier analysis and compared by the Log-Rank test 
regionally different in Asia, Europe, and America, it still can be as high as 23 to $44.9 \%$ [7, 12-14]. Even in PLA patients caused by Klebsiella pneumonia, the incidence of DM is higher as $49.7 \%$. Unexpectedly, this number is likely to grow in recent years with the increasing PLA [14]. In this study, the ratio reached $26.87 \%$.

PLA and DM are high wasting diseases and often progress rapidly when both occur. Meanwhile, the development of the PLA has unique characteristics, and the mortality rate is high during the onset period [15]. Combined with DM in PLA patients should have a significant impact on overall survival, especially in the short onset period. Researchers believe that the physique of DM patients tends to be fragile when suffered from PLA, the condition will be complicated and the mortality will be higher [16]. They discovered that PLA patients with and without DM had a mortality rate of 24.8 and $18.0 \%$ within 30 days after discharge, respectively [16]. However, other studies agreed that DM was not an independent risk factor for prognosis in PLA patients $[3,6]$. In this study, the six-month follow-up was performed on 227 PLA patients who were retrospectively enrolled. We found that the overall mortality rate was $10.57 \%$ within 6 months after discharge, which was slightly lower than similar studies [15]. Moreover, DM existed as the only independent risk factor for six-month survival in PLA patients after hospitalization in this cohort and other high-risk factors, such as age $>60$ years, cirrhosis, diameter of the abscess, and gas-forming were not statistically significant in the multivariate model $[15,17]$. Compared with $7.83 \%$ in PLA patients without DM, the mortality dramatically increased to $18.03 \%$ in patients with DM. However, in the further subgroups, poor-control of glycaemia didn't reduce the short-term survival, but the recurrence rate of PLA within 3 months after discharge showed a 3 -fold increase $(13.16 \%$ vs. $4.35 \%)$. It can be interpreted as poor-control of glycaemia inducing a higher infection and more abscess numbers by a recent similar study [7].

In PLA patients with DM, blood pressure was significantly high, which suggested that these cases had vascular diseases [18]. Although there was no statistical difference in diabetic vascular diseases between the two subgroups, the incidence of micro-angiopathy in the poor-control group (21.05\%) was significantly higher than in the good-control group $(8.70 \%)$, which might be due to the metabolic disorders in DM patients. Unexpectedly, leukocytes count showed a higher abnormal at admission in the Non-DM group, which might be related to the heavier inflammatory status in this group. Bacterial culture revealed that Klebsiella pneumonia and Escherichia coli were still the two most common infectious pathogens, whether or not combined with DM [6, 12, 19]. Interestingly, pus culture results illustrated 2 cases of Candida spp. infection in the DM group. Candida spp. is rare in PLA, but it is highly related to mortality [20]. The infection rate of candida spp. in this study was only $0.88 \%(2 / 227)$, but all occurred in the DM group, probably due to the vulnerable immune system in these cases. Besides, DM patients may be more common in gas-forming [21], but the slightly higher rate has been found in this study (24.59\% vs. $18.07 \%$ ).

The administration of PLA with DM is commonly more complex than simple PLA. Hyperglycemia in tissue easily causes cell hyperosmotic, regeneration and repair function weakening, which then may delay puncture healing [22]. In our study, PLA patients without DM were mainly operated with percutaneous drainage, while in DM group, percutaneous drainage and simple conservative management were mainly used. Interestingly, in further subgroups, patients with poor blood glycemic control were mainly performed with percutaneous drainage, while patients with good control were mostly treated with the conservative method. It seems that the diameter of abscesses in the poor-controlled group is generally larger in this study [23]. Meanwhile, the use of steroid hormone and immune response enhancers were significantly higher in the DM group, which may be related to the decreased and vulnerable immune system in DM patients. In the poor-control of glycaemia group, PLA patients with a maximum diameter of abscess $\geq 5 \mathrm{~cm}$ accounted for $65.79 \%$, while those in good-control group were only $52.17 \%$ [24]. It was notable that the poorcontrolled group had a higher proportion of combined antibiotic administration and the good-controlled group presented with a single antibiotic [7]. In addition, the hospitalization cost in the poor-controlled group was twice that of the good-controlled group, although there was no significant difference in hospital stay between the two groups [25]. Previous studies have shown that gas-forming nature and higher creatinine are risk predictors of fatality for PLA patients [6]. However, in our multivariate model, they were not illustrated to be independent risk factors affecting six-month survival after hospitalization.

The limitations of this study are mainly focused on its retrospective and single-centered traits, while because of its large sample size, the conclusions we have gained can still be used as a helpful reference for other researchers and clinicians, especially further enriching the experience of diagnosis and treatment of PLA patients with DM in northwestern China. Moreover, as the follow-up time in the present study was only 6 months, further longer follow-up and expanded sample size will be needed to comment on the long-term administrations and outcomes of PLA patients with DM.

\section{Conclusions}

Underlying with DM is common in PLA patients, whose epidemiology and administrations show unique 
specificities. PLA patients with DM have a higher incidence of hypertension and Candida spp. infection. In the DM group, patients were mainly treated with the conservative method and more combined antibiotics use. During the follow-up period, the DM group showed a higher mortality rate than that in the Non-DM group. It was found that DM aggravated six-month mortality after hospitalization and presented to be the only independent risk factor for the short-term survival in PLA patients. Moreover, poor-control of glycaemia level might cause different treatments and relapse PLA more frequently. Hence, DM is an important risk factor for PLA patients and effective management of blood glucose levels should be recommended.

\section{Supplementary information}

Supplementary information accompanies this paper at https://doi.org/10. 1186/s12879-020-4855-9.

Additional file 1: Table S1. Flowchart for selection of 227 PLA patients in this study.

\section{Abbreviations}

ALB: Albumin; ALT: Alanine aminotransferase; APTT: Activated partial thromboplastin time; AST: Aspartate aminotransferase; BUN: Blood urea nitrogen; Cr: Creatinine; DM: Diabetes mellitus; Non-DM: Non-diabetes Mellitus; PLA: Pyogenic liver abscess; PT: Prothrombin time; TBIL: Total bilirubin; WBC: White blood cell

\section{Acknowledgements}

We thank supports from the Department of Hepatobiliary Surgery of the First Affiliated Hospital of Xi'an Jiaotong University and China Scholarship Council.

\section{Authors' contributions}

Conceptualization: RW, XZ2; Data curation: ZD, XZ1, JZ1, JB, YL1. Formal analysis: ZD, JZ1, XZ1; Validation: $X Z 1$; Funding acquisition: RW; Investigation: ZD, XZ1, JZ1, JB, JZ2, RY; Methodology: ZD, XZ1, JZ1, JB, JZ2, RY; Project administration: XZ2, RW; Resources: ZW, YL2; Supervision: RW, XZ2; Visualization: ZD, RW; Writing - original draft: ZD; Writing - review \& editing: RW. All authors read and approved the final manuscript.

\section{Funding}

This work was supported by a grant from the Ministry of Education Innovation Team Development Program of China (No. IRT16R57, YL2).

\section{Availability of data and materials}

All data used or analyzed in this study are included in this published article.

\section{Ethics approval and consent to participate}

This study was approved by the Ethics Committee of the First Affiliated Hospital of Xi'an Jiaotong University (XJTU1AF2015LSL-057). Written informed consent were waived as a retrospective research. There was no further permission from the hospital.

\section{Consent for publication}

Not applicable.

\section{Competing interests}

The authors declare that they have no competing financial interests.

\section{Author details}

${ }^{1}$ National-Local Joint Engineering Research Center for Precision Surgery \& Regenerative Medicine, Shaanxi Provincial Center for Regenerative Medicine and Surgical Engineering, First Affiliated Hospital of Xi'an Jiaotong University, Xi'an 710061, Shaanxi Province, China. ${ }^{2}$ Department of Hepatobiliary Surgery,
First Affiliated Hospital of Xi'an Jiaotong University, Xi'an 710061, Shaanxi Province, China.

Received: 21 October 2019 Accepted: 6 February 2020

Published online: 17 February 2020

\section{References}

1. Lo JZ, Leow JJ, Ng PL, Lee HQ, Mohd Noor NA, Low JK, Junnarkar SP, Woon WW. Predictors of therapy failure in a series of 741 adult pyogenic liver abscesses. J Hepatobiliary Pancreat Sci. 2015;22(2):156-65.

2. Meddings L, Myers RP, Hubbard J, Shaheen AA, Laupland KB, Dixon E, Coffin C, Kaplan GG. A population-based study of pyogenic liver abscesses in the United States: incidence, mortality, and temporal trends. Am J Gastroenterol. 2010;105(1):117-24.

3. Tsai FC, Huang YT, Chang LY, Wang JT. Pyogenic liver abscess as endemic disease, Taiwan. Emerg Infect Dis. 2008;14(10):1592-600.

4. Chen YC, Lin CH, Chang SN, Shi ZY. Epidemiology and clinical outcome of pyogenic liver abscess: an analysis from the National Health Insurance Research Database of Taiwan, 2000-2011. J Microbiol Immunol Infect. 2016; 49(5):646-53.

5. Gallagher MC, Andrews MM. Postdischarge outcomes of pyogenic liver abscesses: single-center experience 2007-2012. Open Forum Infect Dis. 2017;4(3):ofx159.

6. Foo NP, Chen KT, Lin HJ, Guo HR. Characteristics of pyogenic liver abscess patients with and without diabetes mellitus. Am J Gastroenterol. 2010; 105(2):328-35.

7. Li W, Chen H, Wu S, Peng J. A comparison of pyogenic liver abscess in patients with or without diabetes: a retrospective study of 246 cases. BMC Gastroenterol. 2018;18(1):144

8. Masarone M, Rosato V, Aglitti A, Bucci T, Caruso R, Salvatore T, Sasso FC, Tripodi MF, Persico M. Liver biopsy in type 2 diabetes mellitus: Steatohepatitis represents the sole feature of liver damage. PLoS One. 2017; 12(6):e0178473.

9. Gonzalez-Regueiro JA, Moreno-Castaneda L, Uribe M, Chavez-Tapia NC. The role of bile acids in glucose metabolism and their relation with diabetes. Ann Hepatol. 2017;16(Suppl. 1: s3-105):16-21.

10. Mithieux G. Metabolic effects of portal vein sensing. Diabetes Obes Metab. 2014;16(Suppl 1):56-60.

11. Tian LT, Yao K, Zhang XY, Zhang ZD, Liang YJ, Yin DL, Lee L, Jiang HC, Liu LX. Liver abscesses in adult patients with and without diabetes mellitus: an analysis of the clinical characteristics, features of the causative pathogens, outcomes and predictors of fatality: a report based on a large population, retrospective study in China. Clin Microbiol Infect. 2012;18(9):E314-30.

12. Serraino C, Elia C, Bracco C, Rinaldi G, Pomero F, Silvestri A, Melchio R, Fenoglio LM. Characteristics and management of pyogenic liver abscess: a European experience. Medicine. 2018:97(19):e628.

13. Mukthinuthalapati V, Attar BM, Parra-Rodriguez L, Cabrera NL, Araujo T, Gandhi S. Risk factors, management, and outcomes of pyogenic liver abscess in a US safety net hospital. Dig Dis Sci. 2019. https://doi.org/10. 1007/s10620-019-05851-9.

14. Qian Y, Wong CC, Lai S, Chen H, He X, Sun L, Wu J, Zhou J, Yu J, Liu W, et al. A retrospective study of pyogenic liver abscess focusing on Klebsiella pneumoniae as a primary pathogen in China from 1994 to 2015. Sci Rep. 2016;6:38587.

15. Poovorawan K, Pan-Ngum W, Soonthornworasiri N, Kulrat C, Kittitrakul C, Wilairatana P, Treeprasertsuk S, Kitsahawong B, Phaosawasdi K. Burden of liver abscess and survival risk score in Thailand: a population-based study. Am J Trop Med Hyg. 2016;95(3):683-8.

16. Thomsen RW, Jepsen P, Sorensen HT. Diabetes mellitus and pyogenic liver abscess: risk and prognosis. Clin Infect Dis. 2007:44(9):1194-201.

17. Jun $\mathrm{CH}$, Yoon JH, Wi JW, Park SY, Lee WS, Jung SI, Park CH, Joo YE, Kim HS, Choi SK, et al. Risk factors and clinical outcomes for spontaneous rupture of pyogenic liver abscess. J Dig Dis. 2015;16(1):31-6.

18. Ohishi M. Hypertension with diabetes mellitus: physiology and pathology. Hypertens Res. 2018:41(6):389-93.

19. Xu J, Zhou X, Zheng C. The geriatric nutritional risk index independently predicts adverse outcomes in patients with pyogenic liver abscess. BMC Geriatr. 2019:19(1):14.

20. Ruiz-Hernandez JJ, Leon-Mazorra M, Conde-Martel A, Marchena-Gomez J, Hemmersbach-Miller M, Betancor-Leon P. Pyogenic liver abscesses: mortality-related factors. Eur J Gastroenterol Hepatol. 2007;19(10):853-8. 
21. Thng CB, Tan YP, Shelat VG. Gas-forming pyogenic liver abscess: a world review. Ann Hepatobiliary Pancreat Surg. 2018;22(1):11-8.

22. Baltzis D, Eleftheriadou I, Veves A. Pathogenesis and treatment of impaired wound healing in diabetes mellitus: new insights. Adv Ther. 2014;31(8):817-36.

23. Mobasher-Jannat A, Akhavan-Moghadam J. Percutaneous drainage for giant pyogenic liver abscess-does size matter? Am J Surg. 2017;214(4):770

24. Ko MC, Lin WH, Martini S, Chang YH, Chiu CT, Li CY. A cohort study of age and sex specific risk of pyogenic liver abscess incidence in patients with type 2 diabetes mellitus. Medicine. 2019;98(17):e15366.

25. Kang SC, Hwang SJ. Impact of advanced age on inpatients with pyogenic liver abscess in Taiwan: a nationwide claim-based analysis. J Chin Med Assoc. 2011;74(12):539-43.

\section{Publisher's Note}

Springer Nature remains neutral with regard to jurisdictional claims in published maps and institutional affiliations.

Ready to submit your research? Choose BMC and benefit from:

- fast, convenient online submission

- thorough peer review by experienced researchers in your field

- rapid publication on acceptance

- support for research data, including large and complex data types

- gold Open Access which fosters wider collaboration and increased citations

- maximum visibility for your research: over $100 \mathrm{M}$ website views per year

At $\mathrm{BMC}$, research is always in progress.

Learn more biomedcentral.com/submissions 